\title{
Índice SPAD no limbo foliar da batateira sob parcelamentos e doses de nitrogênio e potássio ${ }^{1}$
}

\author{
SPAD index in the leaves of potato under splitting and doses of nitrogen and \\ potassium
}

\author{
Adriana Dias Cardoso ${ }^{2 *}$, Marco Antônio Resende Alvarenga ${ }^{3}$, Thiago Lima Melo ${ }^{4}$, Anselmo Eloy Silveira Viana \\ e Sylvana Naomi Matsumoto 5
}

\begin{abstract}
Resumo - Com o objetivo de avaliar a intensidade do verde no limbo foliar da batateira submetido a doses e parcelamentos de nitrogênio e potássio foi conduzido este experimento no município de Mucugê-BA. Foram utilizadas 3 doses de N e K ( $75 \%$ da dose recomendada; dose recomendada de acordo com a análise do solo; $125 \%$ da dose recomendada;) e 5 épocas de aplicação ( $100 \%$ no plantio; $1 / 3$ no plantio e $2 / 3$ na tuberização; $50 \%$ no plantio e $50 \%$ na tuberização; $1 / 3$ no plantio, $1 / 3$ na tuberização e 1/3 25 dias após a tuberização; 1/4 no plantio, 1/4 na tuberização, 1/4 25 dias após a tuberização e $1 / 450$ dias após a tuberização). O delineamento experimental utilizado foi em blocos ao acaso, em esquema fatorial 5 x 3 , com quatro repetições. Foram utilizados tubérculos das cultivares Ágata, Monalisa e Vivaldi, uniformemente brotados, foram plantados em espaçamento $0,8 \mathrm{~m}$ x 0,3 $\mathrm{m}$ de acordo com o recomendado para a cultura. Foi medida, ao longo do ciclo, a intensidade do verde em folhas de batateira: 30; 55 e 80 dias após o plantio, utilizando-se o medidor indireto de clorofila SPAD-502. As doses de N e K não influenciaram no índice SPAD, nas cultivares de batata ao longo do ciclo. O índice SPAD pode ser usado como ferramenta para indicar a época mais correta de se fazer a colheita dos tubérculos de batata.
\end{abstract}

Palavras-chave - Batata. Clorofila. Plantas-efeito do nitrogênio. Plantas efeito do potássio.

\begin{abstract}
With the purpose of assessing the leaf greenness of potato under application times and doses of nitrogen and potassium, this experiment was carried out in the municipality of Mucugê-BA.Three doses of $\mathrm{N}$ and $\mathrm{K}$ were used (75\% of the recommended dose; the recommended dose according to soil analysis; $125 \%$ of the recommended dose). Five application times ( $100 \%$ upon planting; $1 / 3$ upon planting and $2 / 3$ upon tuberization; $50 \%$ upon planting and $50 \%$ upon tuberization; $1 / 3$ upon planting, $1 / 3$ upon tuberization and 1/3 25 days after tuberization; $1 / 4$ upon planting, 1/4 upon tuberization, $1 / 425$ days after tuberization and 1/4 50 days after tuberization were utilized. The experimental design was factorial $(5 \times 3)$, with plots arranged in randomized blocks with four replications. Tubercles from Ágata, Monalisa and Vivaldi cultivars, uniformly budded, were planted with spacing of $0.8 \times 0.3 \mathrm{~m}$ on a prepared soil as recommended for the culture. Was measured, throughout the cycle, the leaf greenness of potato, 30, 55 and 80 days after planting, using the indirect chlorophyll meter SPAD. The doses of N and $\mathrm{K}$ did not influence SPAD index, in potato cultivars over the cycle. The SPAD index can be used as a tool to indicate the most correct time for tubercule potato harvest.
\end{abstract}

Key words - Potato. Chlorophyll. Plants-effect of nitrogen. Plant effect of potassium.

\footnotetext{
* Autor para correspondência

'Recebido para publicação em 01/09/2009; aprovado em 21/01/2011

Parte de tese de Doutorado em Fitotecnia do primeiro autor

'Universidade Estadual do Sudoeste da Bahia, Laboratório de Melhoramento e Produção Vegetal, Estrada do Bem Querer, km 04, Caixa Postal 95, Vitória da Conquista-BA, Brasil, 45.031-900, adridk@bol.com.br, ae-viana@uol.com.br

${ }^{3}$ Prof. Dr. Aposentado da Universidade Federal de Lavras, Estrada do Bem Querer, km 04, Caixa Postal 95, Vitória da Conquista-BA, Brasil, 45.031900, marcoalvarenga@ufla.br

${ }^{4}$ Engenheiro Agrônomo, Rua Paulo Filadelfo, n.7, Apto 401, Candeias, Vitória da Conquista-BA, Brasil, 45.028-355, thiagolimelo@bol.com.br

${ }^{5}$ Universidade Estadual do Sudoeste da Bahia, Laboratório de Fisiologia Vegetal, Estrada do Bem Querer, km 04, Caixa Postal 95, Vitória da Conquista-

BA, Brasil,45.031-900, naomi@uesb.br
} 


\section{Introdução}

A batata (Solanum tuberosum L.) é a quarta fonte de alimento mais importante no mundo, superada apenas pelo trigo, arroz e milho. No Brasil, é a principal hortaliça com área plantada de aproximadamente 145 mil hectares e com produtividade média de $23,4 \mathrm{t} \mathrm{ha}^{-1}$ (FAO, 2010).

Dentre os fatores que podem favorecer o aumento desta produtividade, pode-se citar a utilização de fertilizantes, principalmente o nitrogênio que é considerado nutriente de maior impacto na produtividade das culturas, por está relacionado diretamente com a fotossíntese e ao crescimento do compartimento vegetativo da planta (YIN et al., 2003).

Para Kleinhenz (2001) e Oliveira (2000), a aplicação de nitrogênio deve ser feita em cobertura apenas em uma única aplicação. Entretanto, com base nos estudos de perda de nitrogênio, Barcelos et al. (2007), Steiber e Mahler (2003) e Vieira et al. (2002) sugerem o parcelamento da dose desse nutriente em mais de uma vez após o plantio, sendo uma alternativa viável em solos de textura grosseira e sob irrigação. Para Steiber e Mahler (2003), é necessário fracionar o $\mathrm{N}$ até cinco parcelamentos, pelo fato das raízes apresentarem-se superficiais e pela fácil perda de nitrogênio por lixiviação.

O parcelamento da dose recomendada de $\mathrm{N}$ pode melhorar o manejo de fertilização nitrogenada, sendo essa decisão obtida pela avaliação do estado de $\mathrm{N}$ da batata. Essa avaliação pode ser feita pela análise do teor de $\mathrm{N}$ na massa seca das folhas ou pela determinação indireta do teor de clorofila (FONTES, 2001).

$\mathrm{Na}$ década de 90 foi disponibilizado um equipamento capaz de gerar grandezas relacionadas com os teores de clorofila, o clorofilômetro Soil Plant Analysis Development (SPAD-502, Minolta, Japão). Este aparelho tem sido investigado para a avaliação da nutrição nitrogenada das culturas diretamente no campo, agregando vantagens como a simplicidade no uso, além de possibilitar uma avaliação não-destrutiva do tecido foliar (ARGENTA et al., 2001; ARGENTA et al., 2002; DIDONET et al., 2005).

De acordo com Fontes e Silva (2006), os teores de $\mathrm{N}$ na folha são correlacionados positivamente com a taxa fotossintética da planta, tendo a clorofila como pigmento que atua diretamente no processo de fotossíntese. Deste modo, o teor de clorofila na planta, em certa fase do seu ciclo, tem sido relacionado com o estado de nitrogênio de algumas culturas como citrus (GIRARDI; MOURÃO FILHO, 2004; VALE; PRADO, 2009;), feijão (SILVEIRA et al., 2003), melão (ORSINI et al., 2009), tomate (FERREIRA et al., 2006), beterraba açucareira (SEXTON; CARROLL, 2002) e batata (SAMPAIO JÚNIOR et al, 2008; SILVA et al., 2009; WU et al., 2007). A análise da intensidade do verde das folhas de diversas espécies, inclusive batata pode ser realizada com equipamento ou clorofilômetro portátil (RODRIGUES et al., 2000) e deve ser determinada em uma folha completamente expandida da batata.

Assim, o índice SPAD pode ser considerado como ferramenta capaz de indicar a necessidade da aplicação do $\mathrm{N}$, desde que se conheça o nível crítico deste elemento na planta, apesar de existirem alguns fatores que podem afetar este índice, como condições edafoclimáticas, cultivar, variações anuais e locais (BULLOCK; ANDERSON, 1998).

Dessa maneira, como são escassos os trabalhos de pesquisa abordando índice SPAD para a cultura da batata no Brasil objetivou-se determinar a intensidade do verde no limbo foliar da batateira submetidos a doses e parcelamentos de nitrogênio e potássio, ao longo do ciclo da cultura.

\section{Material e métodos}

O experimento foi instalado na Fazenda Progresso II, localizada na Rodovia BA 142, km 137, distrito de Cascavel, no município de Mucugê, BA, situado à latitude $13^{\circ} 00^{\prime} 19^{\prime}$ ' $\mathrm{S}$ e longitude $41^{\circ} 22^{\prime} 15^{\prime}$ " W e com altitude de $984 \mathrm{~m}$. A precipitação média é de $681,7 \mathrm{~mm}$, em um Latossolo Amarelo, com topografia plana, o qual apresentou as seguintes características na camada 0-20 cm de profundidade, amostrada antes da instalação do experimento, conforme a Tabela 1.

O preparo do solo foi feito de acordo com o recomendado para a cultura da batata. O solo foi arado e gradeado. A calagem foi realizada 60 dias antes do plantio.

O experimento foi dividido em 3 ensaios. Para cada ensaio foram utilizados cultivares de batata de ciclo diferenciado: Ágata (ciclo precoce a muito precoce), Monalisa (ciclo muito precoce) e Vivaldi (ciclo precoce).

O delineamento experimental utilizado foi o de blocos ao acaso, em esquema fatorial 5 × 3, totalizando 15 tratamentos, com 4 repetições. Os tratamentos foram constituídos por três doses de nitrogênio e potássio e cinco épocas de aplicação de adubação com nitrogênio e potássio.

a) Doses de nitrogênio e potássio utilizadas:

1. $105 \mathrm{~kg} \mathrm{ha}^{-1}$ de $\mathrm{N}$ e $210 \mathrm{~kg} \mathrm{ha}^{-1}$ de $\mathrm{K}$; 
Tabela 1 - Análise química e física de amostra do solo da área experimental $(0-20 \mathrm{~cm})$ realizada após a calagem

\begin{tabular}{|c|c|}
\hline Determinação & Valores \\
\hline $\mathrm{pH}$ em $\mathrm{H}_{2} \mathrm{O}(1: 2,5)$ & 5,2 \\
\hline $\mathrm{P}\left(\mathrm{mg} \mathrm{dm}^{-3}\right)^{2 /}$ & 48,0 \\
\hline $\mathrm{K}^{+}\left(\mathrm{cmol}_{\mathrm{c}} \mathrm{dm}^{-3}\right)^{\underline{2} /}$ & 0,18 \\
\hline $\mathrm{Al}^{3+}\left(\mathrm{cmol}_{\mathrm{c}} \mathrm{dm}^{-3}\right)^{3 /}$ & 0,3 \\
\hline $\mathrm{Ca}^{2+}\left(\mathrm{cmol}_{\mathrm{c}} \mathrm{dm}^{-3}\right)^{3 /}$ & 1,0 \\
\hline $\mathrm{Mg}^{2+}\left(\mathrm{cmol}_{\mathrm{c}} \mathrm{dm}^{-3}\right)^{3 /}$ & 1,5 \\
\hline $\mathrm{H}^{++} \mathrm{Al}^{3+}\left(\mathrm{cmol}_{\mathrm{c}} \mathrm{dm}^{-3}\right)^{4 /}$ & 1,7 \\
\hline S.B $\left(\mathrm{cmol}_{\mathrm{c}} \mathrm{dm}^{-3}\right)$ & 2,7 \\
\hline $\mathrm{m}(\%)$ & 10,0 \\
\hline $\mathrm{V}(\%)$ & 61,0 \\
\hline CTC efetiva $\left(\mathrm{cmol}_{\mathrm{c}} \mathrm{dm}^{-3}\right)$ & 3,0 \\
\hline CTC a pH 7,0 $\left(\mathrm{cmol}_{\mathrm{c}} \mathrm{dm}^{-3}\right)$ & 4,4 \\
\hline M.O $\left(\mathrm{g} \mathrm{dm}^{-3}\right)$ & 0,0 \\
\hline $\mathrm{Cu}^{++}\left(\mathrm{mg} \mathrm{dm}^{-3}\right)$ & 2,60 \\
\hline $\mathrm{Mn}^{++}\left(\mathrm{mg} \mathrm{dm}^{-3}\right)$ & 1,40 \\
\hline $\mathrm{Zn}^{++}\left(\mathrm{mg} \mathrm{dm}^{-3}\right)$ & 2,70 \\
\hline $\mathrm{Fe}^{++}\left(\mathrm{mg} \mathrm{dm}^{-3}\right)$ & 24,00 \\
\hline \multicolumn{2}{|c|}{ Composição granulométrica (tfsa $\mathrm{g} \mathrm{kg}^{-1}$ ) } \\
\hline Areia grossa & 460 \\
\hline Areia fina & 360 \\
\hline Silte & 20 \\
\hline Argila & 160 \\
\hline
\end{tabular}

${ }^{2 /}$ Extrator Mehlich - 1; ${ }^{3 /}$ Extrator $\mathrm{KCl} 1 \mathrm{~mol} \mathrm{~L}^{-1}$; ${ }^{4}$ Extrator Solução SMP, $\mathrm{pH} 7,5$ a 7,7

2. $140 \mathrm{~kg}$ de $\mathrm{N}$ e $280 \mathrm{~kg}$ de $\mathrm{K}$ (dose recomendada de acordo com a análise do solo);

3. $175 \mathrm{~kg} \mathrm{ha}^{-1}$ de $\mathrm{N}$ e $350 \mathrm{~kg} \mathrm{ha}^{-1}$ de $\mathrm{K}$

b) Épocas de aplicação de adubação com nitrogênio e potássio:

1. $100 \%$ no plantio;

2. $1 / 3$ no plantio e $2 / 3$ na tuberização (28 dias após o plantio);

\section{3. $50 \%$ no plantio e $50 \%$ na tuberização;}

4. $1 / 3$ no plantio, $1 / 3$ na tuberização e $1 / 3$ aos 25 dias após a tuberização;

5. 1/4 no plantio, 1/4 na tuberização, 1/4 aos 25 dias após a tuberização e 1/4 aos 50 dias após a tuberização).

Cada parcela constituiu-se de seis fileiras contendo sete plantas, num total de 42 plantas por parcela, sendo utilizadas apenas seis plantas por parcela, em uma área útil de $1,44 \mathrm{~m}^{2}$. Foram tomadas quatro fileiras como bordadura externa, margeando-se cada parcela do experimento.

Utilizou-se tubérculos-semente previamente brotados, com peso médio de 70 a $80 \mathrm{~g}$, plantados manualmente nos dias 2 a 3 de maio de 2006. O espaçamento adotado foi $0,3 \mathrm{~m}$ entre plantas e $0,8 \mathrm{~m}$ entre linhas de plantio, resultando em uma população de 41.667 plantas $^{-1}$.

A adubação dos fertilizantes no sulco de plantio foi realizada manualmente, obedecendo todos os tratamentos. Utilizou-se o adubo 4-14-8 e o superfosfato simples na primeira aplicação para todos os tratamentos. Nas aplicações dos parcelamentos 2; 3; 4 e 5, aplicou-se uréia $(46 \%$ de $\mathrm{N})$ e cloreto de potássio $\left(59 \%\right.$ de $\left.\mathrm{K}_{2} \mathrm{O}\right)$, como fonte de nitrogênio e potássio, respectivamente.

O controle fitossanitário foi feito por meio de aplicações preventivas e de controle com defensivos químicos, sempre que necessário. Foram feitas aplicações no solo e ou pulverização foliar com defensivos agrícolas (fungicidas e inseticidas). A aplicação de agroquímicos seguiu as práticas usadas na região.

A irrigação foi realizada por meio de um sistema de irrigação por pivô central, visando atender às necessidades hídricas do sistema solo-planta.

As leituras do índice SPAD foram realizadas no período matinal, no folíolo terminal da quarta folha completamente expandida, por meio do medidor indireto de clorofila SPAD-502 (Soil Plant Analysis Development), Minolta Câmera Co. Ltd. Japão. Utilizouse seis plantas úteis de cada parcela, 30; 55 e 80 dias após o plantio. Os resultados foram expressos em unidade SPAD.A análise estatística foi realizada utilizando-se o software SISVAR (FERREIRA, 2003), procedendo-se à Análise de Variância, com as médias comparadas pelo teste de Tukey a $5 \%$ de probabilidade.

\section{Resultados e discussão}

O índice SPAD, avaliado 30 dias após o plantio (primeiro estádio avaliado), não apresentou diferenças significativas entre as doses e os parcelamentos de $\mathrm{N}$ e K, para as cultivares Ágata e Vivaldi. Para a cultivar Monalisa, houve diferença significativa apenas na intensidade do verde entre os parcelamentos da adubação. $\mathrm{O}$ menor valor do índice SPAD foi encontrado nas plantas submetidas ao parcelamento 2 (1/3 e 2/3 na tuberização da adubação nitrogenada e potássica no plantio, respectivamente), comparado com a aplicação total da adubação (TAB. 2). 
Tabela 2 - Médias de índice SPAD (unidade SPAD) amostrado 30 dias após o plantio, nas cultivares de batata Ágata, Monalisa e Vivaldi em função de doses e do parcelamento da adubação

\begin{tabular}{|c|c|c|c|c|c|c|}
\hline \multicolumn{7}{|c|}{ Cultivar Ágata } \\
\hline \multirow{2}{*}{ Dose } & \multicolumn{5}{|c|}{ Parcelamento } & \multirow{2}{*}{ Média } \\
\hline & 1 & 2 & 3 & 4 & 5 & \\
\hline $75 \%$ da dose recom. & 46,68 & 46,68 & 46,33 & 45,78 & 45,65 & $46,22 \mathrm{~A}$ \\
\hline Recomendada & 47,75 & 44,80 & 46,65 & 46,38 & 45,35 & $46,19 \mathrm{~A}$ \\
\hline $125 \%$ da dose recom. & 47,68 & 46,60 & 47,50 & 47,70 & 47,35 & $47,37 \mathrm{~A}$ \\
\hline Média & $47,37 \mathrm{a}$ & $43,03 \mathrm{a}$ & $46,83 \mathrm{a}$ & $46,62 \mathrm{a}$ & $46,12 \mathrm{a}$ & \\
\hline \multirow[t]{2}{*}{ C.V. $(\%)$} & 7,84 & & & & & \\
\hline & \multicolumn{5}{|c|}{ Cultivar Monalisa } & \\
\hline \multirow{2}{*}{ Dose } & \multicolumn{5}{|c|}{ Parcelamento } & \multirow{2}{*}{ Média } \\
\hline & 1 & 2 & 3 & 4 & 5 & \\
\hline $75 \%$ da dose recom. & 47,50 & 45,08 & 46,68 & 47,10 & 44,10 & $46,09 \mathrm{~A}$ \\
\hline Recomendada & 47,98 & 45,73 & 48,03 & 47,68 & 46,58 & $47,20 \mathrm{~A}$ \\
\hline $125 \%$ da dose recom. & 48,10 & 46,45 & 46,85 & 46,05 & 47,33 & $46,96 \mathrm{~A}$ \\
\hline Média & $47,86 \mathrm{a}$ & $45,75 \mathrm{~b}$ & $47,19 \mathrm{ab}$ & $46,94 \mathrm{ab}$ & $46,00 \mathrm{ab}$ & \\
\hline \multirow[t]{2}{*}{ C.V. $(\%)$} & 3,85 & & & & & \\
\hline & \multicolumn{5}{|c|}{ Cultivar Vivaldi } & \\
\hline \multirow{2}{*}{ Dose } & \multicolumn{5}{|c|}{ Parcelamento } & \multirow{2}{*}{ Média } \\
\hline & 1 & 2 & 3 & 4 & 5 & \\
\hline $75 \%$ da dose recom. & 49,73 & 46,68 & 46,50 & 47,08 & 47,05 & $47,41 \mathrm{~A}$ \\
\hline Recomendada & 48,25 & 47,35 & 47,40 & 48,80 & 47,00 & $47,76 \mathrm{~A}$ \\
\hline $125 \%$ da dose recom. & 49,88 & 48,08 & 47,95 & 46,58 & 47,43 & $47,98 \mathrm{~A}$ \\
\hline Média & $49,29 \mathrm{a}$ & $47,37 \mathrm{a}$ & $47,28 \mathrm{a}$ & $47,49 \mathrm{a}$ & $47,16 \mathrm{a}$ & \\
\hline C.V. $(\%)$ & 4,69 & & & & & \\
\hline
\end{tabular}

*Médias seguidas de mesma letra minúscula nas linhas e maiúsculas nas colunas, não diferem entre si, a 5\% de probabilidade, pelo teste de Tukey; Parcelamento: $1: 100 \%$ no plantio; $2: 1 / 3$ no plantio e $2 / 3$ na tuberização; $3: 50 \%$ no plantio e $50 \%$ na tuberização; $4: 1 / 3$ no plantio, $1 / 3$ na tuberização e 1/3 25 dias após a tuberização; 5: $1 / 4$ no plantio, 1/4 na tuberização, 1/4 25 dias após a tuberização e 1/4 50 dias após a tuberização

Aos 30 dias após o plantio, todas as cultivares apresentaram índice SPAD próximo à média citada por Malavolta et al. (1997), que considera adequado para a cultura da batata, que a quarta ou quinta folha totalmente expandida, um mês após o plantio apresente 49 a 56 unidades SPAD. Rodrigues et al. (2000) determinaram o valor de 39,6 unidades SPAD como o nível crítico associado a dose de $\mathrm{N}$ que propiciou a máxima produção de massa seca da parte aérea da batateira em solução nutritiva, em estufa.

A concentração de $\mathrm{N}$, de clorofilas e as leituras fornecidas pelo SPAD são altamente correlacionadas (SCHRÖDER et al., 2000). A deficiência de N é imediatamente refletida em baixas concentrações de clorofilas as quais são registradas por baixos valores de SPAD.
Aos 55 dias após o plantio não foram observadas diferenças significativas no índice de SPAD entre as doses de $\mathrm{N}$ e K para as três cultivares avaliadas. No entanto, foram constatadas diferenças da intensidade do verde entre os parcelamentos estabelecidos. Na cultivar Ágata, as plantas submetidas ao tratamento em que se forneceu $\mathrm{N}$ e K em uma só aplicação apresentaram folhas mais verdes do que aquelas submetidas ao parcelamento 5 (1/4 no plantio, 1/4 na tuberização, 1/4 25 dias após a tuberização e 1/4 50 dias após a tuberização), isso, provavelmente, ocorreu devido ao fracionamento do nitrogênio, aplicado na tuberização ( 28 dias após o plantio) e a cada 25 dias após o plantio, num total de quatro aplicações. Apesar disso, os valores de SPAD encontrados em todos os tratamentos estão acima aos valores considerados críticos por Silva et al. (2009) e Rodrigues et. al (2000), 42,2 e 39,6 unidades SPAD, respectivamente. 
Na cultivar Monalisa, observou-se que a aplicação total do adubo no plantio também promoveu uma intensidade do verde nas folhas aos 55 dias após o plantio, quando comparada com o parcelamento 4 (1/3 da adubação N e K no plantio, $1 / 3$ na tuberização e $1 / 325$ dias após a tuberização). Na cultivar Vivaldi, o índice de SPAD foi maior quando se usou o parcelamento 3 (50\% no plantio e $50 \%$ na tuberização) em relação aos parcelamentos 4 (1/3 da adubação $\mathrm{N}$ e $\mathrm{K}$ no plantio, $1 / 3$ na tuberização e $1 / 325$ dias após a tuberização), 5 (1/4 no plantio, $1 / 4$ na tuberização, 1/4 25 dias após a tuberização e 1/4 50 dias após a tuberização) e sem parcelamento (TAB. 3).

Essa diferença da intensidade do verde, encontrada nas três cultivares de batata, com o uso do parcelamento, pode ser atribuída pela forma distinta de absorção de $\mathrm{N}$ de cada cultivar. Provavelmente, a depender do material genético, as plantas podem permanecer mais verdes de acordo com a época de fornecimento dos nutrientes e seu mecanismo de absorção. Vos e Bom (1993) encontraram correlação positiva entre adição de nitrogênio e teor de clorofila na folha da batata, indicando que o teor de clorofila na folha está relacionado com o estado de nitrogênio da planta.

No terceiro estádio de avaliação (80 dias após o plantio) não foram verificadas diferenças no índice de SPAD entre doses e parcelamentos para as cultivares Ágata e Monalisa. Contudo, a cultivar Vivaldi apresentou diferenças estatísticas significativas entre doses e parcelamentos. As plantas submetidas às doses mais altas de $\mathrm{N}$ e $\mathrm{K}$ apresentaram folhas mais verde, quando comparadas àquelas que receberam a dose recomendada e as que receberam a menor dose de $\mathrm{N}$ e $\mathrm{K}$. Em relação ao parcelamento de $\mathrm{N}$ e $\mathrm{K}$, as plantas submetidas ao

Tabela 3 - Médias de índice SPAD (unidade SPAD) amostrado 55 dias após o plantio, nas cultivares de batata Ágata, Monalisa e Vivaldi em função de doses e do parcelamento da adubação

\begin{tabular}{|c|c|c|c|c|c|c|}
\hline \multicolumn{7}{|c|}{ Cultivar Ágata } \\
\hline \multirow{2}{*}{ Dose } & \multicolumn{5}{|c|}{ Parcelamento } & \multirow{2}{*}{ Média } \\
\hline & 1 & 2 & 3 & 4 & 5 & \\
\hline $75 \%$ da dose recom. & 39,65 & 39,13 & 38,53 & 40,18 & 37,93 & $39,08 \mathrm{~A}$ \\
\hline Recomendada & 40,38 & 40,55 & 39,83 & 39,63 & 39,45 & $39,97 \mathrm{~A}$ \\
\hline $125 \%$ da dose recom. & 41,15 & 39,08 & 40,70 & 40,28 & 38,40 & $39,92 \mathrm{~A}$ \\
\hline Média & $40,39 \mathrm{a}$ & $39,59 \mathrm{ab}$ & $39,69 \mathrm{ab}$ & $40,03 \mathrm{ab}$ & $38,59 \mathrm{~b}$ & \\
\hline \multirow[t]{2}{*}{ C.V. $(\%)$} & 3,46 & & & & & \\
\hline & \multicolumn{5}{|c|}{ Cultivar Monalisa } & \\
\hline \multirow{2}{*}{ Dose } & \multicolumn{5}{|c|}{ Parcelamento } & \multirow{2}{*}{ Média } \\
\hline & 1 & 2 & 3 & 4 & 5 & \\
\hline $75 \%$ da dose recom. & 40,05 & 38,48 & 39,45 & 38,48 & 39,70 & $39,23 \mathrm{~A}$ \\
\hline Recomendada & 41,25 & 40,33 & 40,93 & 38,43 & 40,25 & $40,24 \mathrm{~A}$ \\
\hline $125 \%$ da dose recom. & 42,43 & 41,43 & 39,80 & 39,33 & 38,95 & $40,39 \mathrm{~A}$ \\
\hline Média & $41,24 \mathrm{a}$ & $40,08 \mathrm{ab}$ & $40,06 \mathrm{ab}$ & $38,75 \mathrm{~b}$ & $39,63 \mathrm{ab}$ & \\
\hline \multirow[t]{2}{*}{ C.V. $(\%)$} & 4,02 & & & & & \\
\hline & \multicolumn{5}{|c|}{ Cultivar Vivaldi } & \\
\hline \multirow{2}{*}{ Dose } & \multicolumn{5}{|c|}{ Parcelamento } & \multirow{2}{*}{ Média } \\
\hline & 1 & 2 & 3 & 4 & 5 & \\
\hline $75 \%$ da dose recom. & 40,90 & 40,45 & 42,15 & 38,85 & 39,80 & $40,43 \mathrm{~A}$ \\
\hline Recomendada & 40,30 & 41,28 & 43,88 & 40,13 & 39,78 & $41,07 \mathrm{~A}$ \\
\hline $125 \%$ da dose recom. & 40,93 & 40,88 & 41,95 & 40,23 & 40,58 & $40,91 \mathrm{~A}$ \\
\hline Média & $40,71 \mathrm{~b}$ & $40,87 \mathrm{ab}$ & $42,66 \mathrm{a}$ & $39,74 \mathrm{~b}$ & $40,05 \mathrm{~b}$ & \\
\hline C.V. $(\%)$ & 3,80 & & & & & \\
\hline
\end{tabular}

*Médias seguidas de mesma letra minúscula nas linhas e maiúsculas nas colunas, não diferem entre si, a 5\% de probabilidade, pelo teste de Tukey; Parcelamento: 1: $100 \%$ no plantio; $2: 1 / 3$ no plantio e $2 / 3$ na tuberização; $3: 50 \%$ no plantio e $50 \%$ na tuberização; $4: 1 / 3$ no plantio, $1 / 3$ na tuberização e 1/3 25 dias após a tuberização; 5: $1 / 4$ no plantio, 1/4 na tuberização, 1/4 25 dias após a tuberização e $1 / 450$ dias após a tuberização 
parcelamento 5 (1/4 aplicado no plantio, $1 / 4$ na tuberização, $1 / 425$ dias após a tuberização e 1/4 50 dias após a tuberização) permaneceram mais verdes do que aquelas que não foram submetidas ao parcelamento (TAB. 4).

Aos 80 dias após o plantio, os valores de índice SPAD variaram entre 32,45 a 35,05 unidades SPAD para cultivar Ágata, 30,07 a 33,54 unidades SPAD para cultivar Monalisa e 31,88 a 34,90 unidades SPAD para cultivar Vivaldi. Esses valores mostram que quando a planta de batata está em um estádio de desenvolvimento avançado, as folhas começam a reduzir gradativamente a coloração verde acentuada. Assim, o índice SPAD pode ser usado como uma ferramenta para indicar a época mais correta de se fazer a colheita dos tubérculos em determinada cultivar.

A utilização do SPAD para avaliar o estado de $\mathrm{N}$ nas folhas da batateira pode ser realizada em poucos minutos, favorecendo o rápido diagnóstico da situação da lavoura, tendo custo mínimo de manutenção, ao contrário de outros testes que exigem a compra sistemática de produtos químicos (PIEKIELEK; FOX, 1992). Ademais, é uma análise não destrutiva, econômica e prática, não necessitando o envio de material para o laboratório.

Nas Tabelas 2; 3 e 4, verifica-se que o mais acentuado incremento no índice SPAD ocorreu aos 30 dias após o plantio, mostrando maior rapidez na utilização do N no início da tuberização (28 dias após o plantio), mesmo o nitrogênio sendo parcelado. No trabalho realizado por Gil et al. (2002), o maior índice SPAD foi encontrado 17 dias após a aplicação de $\mathrm{N}$ com doses de 90 e $180 \mathrm{~kg} \mathrm{ha}^{-1}$, onde as plantas extraíram maiores concentrações de $\mathrm{N}$.

As diferenças da intensidade do verde nas folhas observadas nas cultivares de batata podem ser devido a diferentes respostas à adubação de N e K. Segundo

Tabela 4 - Médias de índice SPAD (unidade SPAD) amostrado 80 dias após o plantio, nas cultivares de batata Ágata, Monalisa e Vivaldi em função de doses e do parcelamento da adubação

\begin{tabular}{|c|c|c|c|c|c|c|}
\hline \multicolumn{7}{|c|}{ Cultivar Ágata } \\
\hline \multirow{2}{*}{ Dose } & \multicolumn{5}{|c|}{ Parcelamento } & \multirow{2}{*}{ Média } \\
\hline & 1 & 2 & 3 & 4 & 5 & \\
\hline $75 \%$ da dose recom. & 32,93 & 32,88 & 33,68 & 30,73 & 34,95 & $33,03 \mathrm{~A}$ \\
\hline Recomendada & 30,63 & 36,03 & 34,43 & 33,78 & 33,45 & $33,66 \mathrm{~A}$ \\
\hline $125 \%$ da dose recom. & 33,80 & 36,23 & 36,63 & 33,23 & 35,95 & $35,17 \mathrm{~A}$ \\
\hline Média & $32,45 \mathrm{a}$ & $35,05 \mathrm{a}$ & $34,91 \mathrm{a}$ & $32,58 \mathrm{a}$ & $34,78 \mathrm{a}$ & \\
\hline C.V. $(\%)$ & 8,42 & & & & & \\
\hline \multicolumn{7}{|c|}{ Cultivar Monalisa } \\
\hline \multirow{2}{*}{ Dose } & \multicolumn{5}{|c|}{ Parcelamento } & \multirow{2}{*}{ Média } \\
\hline & 1 & 2 & 3 & 4 & 5 & \\
\hline $75 \%$ da dose recom. & 34,05 & 31,13 & 32,40 & 31,95 & 33,30 & $32,57 \mathrm{~A}$ \\
\hline Recomendada & 33,83 & 34,70 & 30,75 & 33,78 & 30,90 & $32,79 \mathrm{~A}$ \\
\hline $125 \%$ da dose recom. & 32,75 & 32,63 & 32,70 & 24,48 & 32,70 & $31,05 \mathrm{~A}$ \\
\hline Média & $33,54 \mathrm{a}$ & $32,82 \mathrm{a}$ & $31,95 \mathrm{a}$ & $30,07 \mathrm{a}$ & $32,30 \mathrm{a}$ & \\
\hline C.V. $(\%)$ & 13,69 & & & & & \\
\hline \multicolumn{7}{|c|}{ Cultivar Vivaldi } \\
\hline \multirow{2}{*}{ Dose } & \multicolumn{5}{|c|}{ Parcelamento } & \multirow{2}{*}{ Média } \\
\hline & 1 & 2 & 3 & 4 & 5 & \\
\hline $75 \%$ da dose recom. & 32,10 & 31,75 & 33,00 & 31,63 & 36,48 & $32,99 \mathrm{~B}$ \\
\hline Recomendada & 30,10 & 33,13 & 33,85 & 34,08 & 32,63 & $32,76 \mathrm{~B}$ \\
\hline $125 \%$ da dose recom. & 33,45 & 34,18 & 33,70 & 36,05 & 35,58 & $34,59 \mathrm{~A}$ \\
\hline Média & $31,88 \mathrm{~b}$ & $33,02 \mathrm{ab}$ & $33,52 \mathrm{ab}$ & $33,92 \mathrm{ab}$ & $34,90 \mathrm{a}$ & \\
\hline C.V. $(\%)$ & 6,19 & & & & & \\
\hline
\end{tabular}

*Médias seguidas de mesma letra minúscula nas linhas e maiúsculas nas colunas, não diferem entre si, a 5\% de probabilidade, pelo teste de Tukey; Parcelamento: $1: 100 \%$ no plantio; $2: 1 / 3$ no plantio e $2 / 3$ na tuberização; $3: 50 \%$ no plantio e $50 \%$ na tuberização; $4: 1 / 3$ no plantio, $1 / 3$ na tuberização e 1/3 25 dias após a tuberização; 5: 1/4 no plantio, $1 / 4$ na tuberização, $1 / 425$ dias após a tuberização e 1/4 50 dias após a tuberização 
Peterson et al. (1993), existem fatores que podem afetar leituras de medidor SPAD, como cultivares, estádio de crescimento, condições ambientais (temperatura, estresse hídrico, luz, etc.), deficiência nutricional, entre outros.

Estudo realizado por Minotti et al. (1994) avaliando o estado de nitrogênio em folhas de batateira mostrou que o diagnóstico de $\mathrm{N}$ da batata pode ser realizado pela análise do teor de clorofila nas folhas ou a intensidade do verde utilizando o aparelho portátil SPAD-502.

Na Figura 1, verifica-se que, mesmo utilizando doses diferenciadas de $\mathrm{N}$, o índice SPAD permaneceu semelhante em todos os períodos avaliados, para as cultivares Ágata, Monalisa e Vivaldi. Esse resultado,
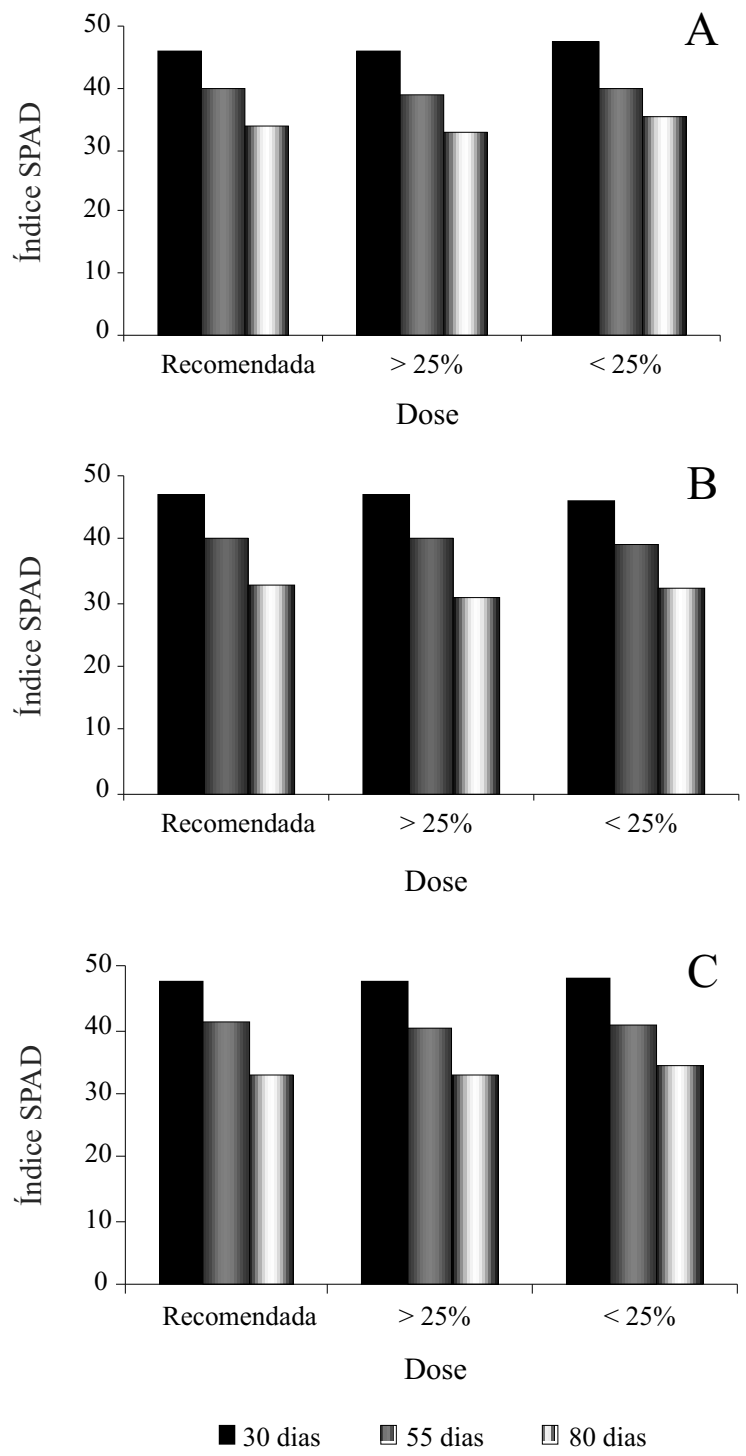

Figura 1 - Índice SPAD amostrado 30, 55 e 80 dias após o plantio, em folhas de batateira cultivar Ágata (A), Monalisa (B) e Vivaldi (C), em função da dose de nitrogênio e potássio provavelmente, ocorreu devido à pequena variação das doses de $\mathrm{N}$ analisadas. No trabalho Gil et al. (2002) encontrou-se incremento na intensidade do verde das folhas de batata, consequentemente aumento nos valores de SPAD, à medida que se elevou a dose de N $(0 ; 90$; 180 e $360 \mathrm{~kg} \mathrm{ha}^{-1}$ ) em cobertura.

Nas Figuras 1 e 2, pode-se observar que o índice de SPAD nas folhas foi reduzido com o avanço do desenvolvimento da batateira em todas as cultivares. Assim, além de diagnosticar o estado de $\mathrm{N}$ na planta, com a avaliação da intensidade do verde nas folhas, por meio do aparelho SPAD, provavelmente, poderá também servir também como indicativo da melhor
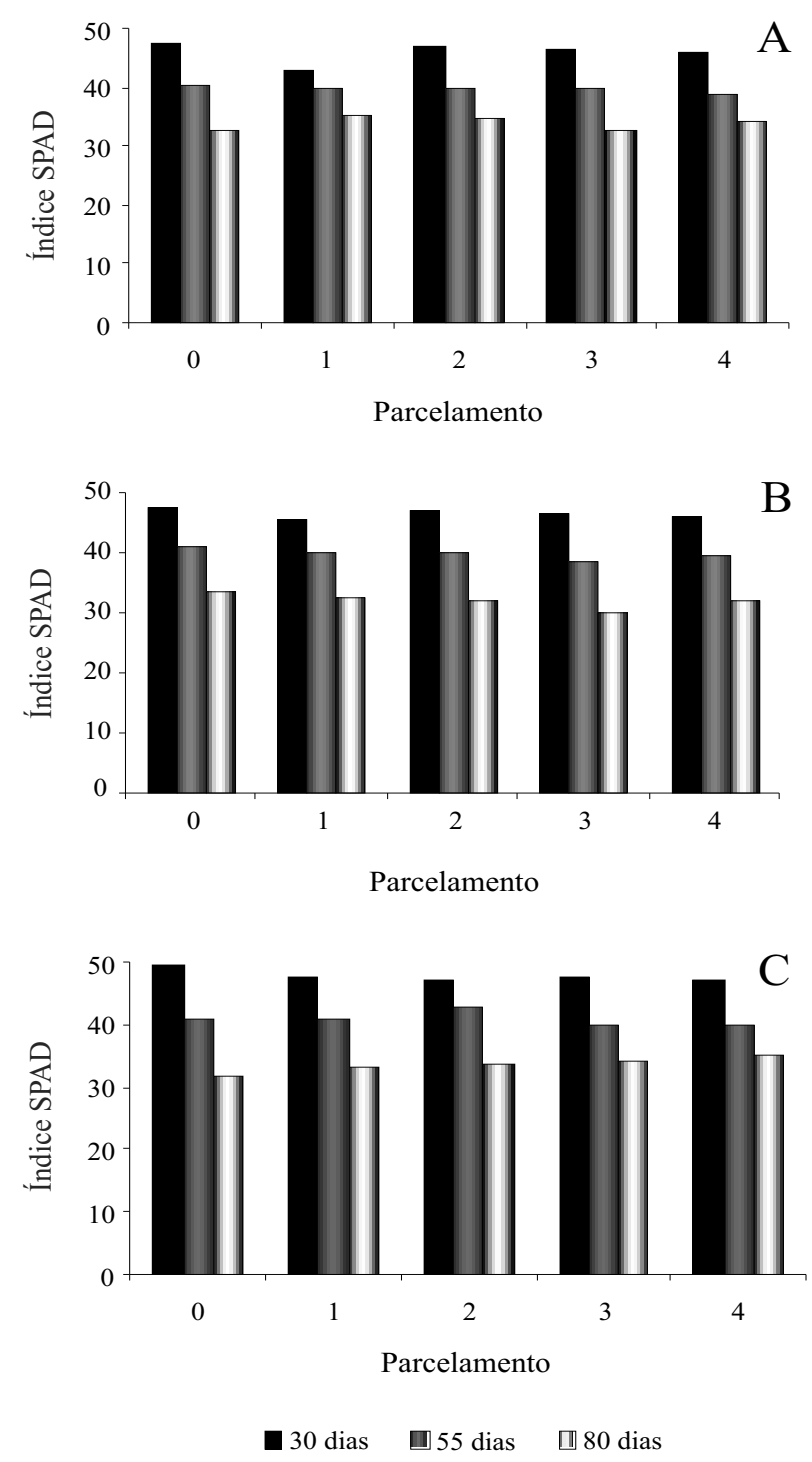

Figura 2 - Índice SPAD amostrado 30, 55 e 80 dias após o plantio, em folhas de batateira cultivar Ágata (A), Monalisa (B) e Vivaldi (C), em função do parcelamento de nitrogênio e potássio 
época de colheita dos tubérculos de batata. De acordo com a coloração da folha o profissional poderá saber se a colheita estará próxima para acontecer ou não. Entretanto, é necessário que se façam estudos relacionando o índice SPAD com a época de colheita.

\section{Conclusões}

1. O índice SPAD não foi influenciado pelas doses de $\mathrm{N}$ e $\mathrm{K}$, nas cultivares de batata ao longo do ciclo;

2. A partir do conhecimento do teor adequado de clorofila de cada cultivar de batata em determinada região é possível realizar o monitoramento sequencial da cor das folhas, para diagnosticar eventual deficiência de $\mathrm{N}$ que poderá ser corrigida com antecedência.

\section{Agradecimentos}

À Universidade Federal de Lavras (UFLA); à Coordenação de Aperfeiçoamento do Pessoal de Nível Superior (CAPES); à Universidade Estadual do Sudoeste da Bahia (UESB) e ao senhor Pedro Hugo Borre, da Fazenda Progresso II.

\section{Referências}

ARGENTA, G. et al. Parâmetros de planta como indicadores de nitrogênio na cultura do milho. Pesquisa Agropecuária Brasileira, v. 37, n. 04, p. 519-527, 2002.

ARGENTA, G. et al. Relação da leitura do clorofilômetro com os teores de clorofila extraível e nitrogênio na folha de milho. Revista Brasileira de Fisiologia Vegetal, v. 13, n. 02, p. 158-167, 2001.

BARCELOS, M. D.; GARCIA, A.; MACIEL JÚNIOR, V. A. Análise de crescimento da cultura de batata submetida ao parcelamento da adubação nitrogenada em cobertura, em um latossolo vermelho-Amarelo. Revista Ciência e Agrotecnologia, v. 31, n. 01, p. 21-27, 2007.

BULLOCK, D. G.; ANDERSON, D. S. Evaluation of the Minolta SPAD 502 chlorophyll meter for nitrogen management in corn. Journal of Plant Nutrition, v. 21, n. 04, p. 741-755, 1998.

DIDONET, A. D. et al. Adubação nitrogenada de cobertura no feijoeiro irrigado: uso do clorofilômetro. Bioscience Journal, v. 21, n. 03, p. 103-111, 2005.

FERREIRA, M. M. M. et al. Índice SPAD e teor de clorofila no limbo foliar do tomateiro em função de doses de nitrogênio e da adubação orgânica, em duas épocas de cultivo. Revista Ceres, v. 53 , n. 305 , p. $76-85,2006$
FERREIRA, D. F. Programa de análises estatísticas (Statistical Analysis Software) e planejamento de experimentos. Lavras: Universidade Estadual de Lavras, 2003.

FONTES, P. C. R; SILVA, M. C. de C. Proposição de uma tabela de cor (UFV 80-Monalisa) para a avaliação do estado de nitrogênio da batateira. Batata Show, v. 06, n. 162006.

FONTES, P. C. R. Diagnóstico do estado nutricional das plantas. Viçosa: Universidade Federal de Viçosa, 2001. 122 p.

FOOD AND AGRICULTURE ORGANIZATION OF THE UNITED NATIONS (FAO). Agricultural production, primary crops. Disponível em: <http://faostat.fao.org/site/339/default. aspx $>$. Acesso em: 10 de maio de 2010.

GIL, P. T. de et al. Índice SPAD para o diagnóstico do estado de nitrogênio e para o prognóstico da produtividade da batata. Horticultura Brasileira, v. 20, n. 04, p. 611-615, 2002.

GIRARDI, E. A.; MOURÃO FILHO, F. A. A. Crescimento inicial de laranjeira "Valencia" sobre dois porta-enxertos em função da adubação nitrogenada no plantio. Revista Brasileira de Fruticultura, v. 26, n. 01, p. 117-119, 2004.

KLEINHENZ, M. Potatoes growing tips and news from the world of research. The Tuber Times, v. 02, n. 01, 2001.

MALAVOLTA, E. et al. Avaliação do estado nutricional das plantas. Piracicaba: Potafos, 1997. 319 p.

MINOTTI, P. L.; HALSETH, D. E., SIECZKA, J. B. Field chlorophyll measurements to assess the nitrogen status of potato varieties. Hortscience, v. 29, n. 12, p. 1497-1500. 1994.

OLIVEIRA, C. A. S. Potato crops growth as affected by nitrogen and plant density. Pesquisa Agropecuária Brasileira, v. 35, n. 05, p. 939-950, 2000.

ORSINI, F.; MEZZETTI, M.; IANQUINTO, G. The use of portable chlorophyll meter for the management of $n$ fertilization in cantaloupe (Cucumis melo L.) grown under transparent polyethylene low tunnels. Acta Horticulturae, v. 807, p. 333-340, 2009.

PETERSON, T. A. et al. Using a chlorophyll meter to improve N management. Lincoln: University of Nebraska, Cooperative Extension, Institute of Agricultural and Natural Resources, 1993.

PIEKIELEK, W. P.; FOX, R. H. Use of a chlorophyll meter to predict sidedress nitrogen requirements for maize. Agronomy Journal, v. 84, n. 01, p. 59-65, 1992.

RODRIGUES, F. A. et al. Nível crítico do índice SPAD na folha da batateira, em solução nutritiva. Horticultura Brasileira, v. 18, p. 764-765, 2000.

SAMPAIO JÚNIOR, J. J. et al. Produção de mini-tubérculo semente de batata, em função de doses de nitrogênio aplicadas ao substrato. Bioscience Journal, v. 24, n. 01, p. 1- 9, 2008.

SEXTON, P.; CARROLL, J. Comparison of SPAD chlorophyll meter readings vs. petiole nitrate concentration in sugar beet. Journal of plant nutrition, v. 25, p. 1975-1986, 2002.

STEIBER, T. D.; MAHLER, R. L. Cropping practices survey: fertilizer results. Idaho: University of Idaho, 2003. 3 p. 
SILVA, M. C. C.; FONTES, P. C. R.; MIRANDA, G. V. Índice spad e produção de batata, em duas épocas de plantio, em função de doses de nitrogênio. Horticultura Brasileira. v. 27, p.17-22. 2009.

SILVEIRA, P. M. et al. Uso de clorofilômetro como indicador da necessidade de adubação nitrogenada em cobertura no feijoeiro. Pesquisa Agropecuária Brasileira, v. 38, n. 09, p. 1083-1087, 2003.

SCHRÖDER, J. J. et al. Does the crop or the soil indicate how to save nitrogen in maize production? Reviewing the state of the art. Field Crops Research, Madison, v. 66, n. 02, p. 151-164, 2000.

VALE, D. W.; PRADO, R. de M. Adubação com NPK e o estado nutricional de 'citrumelo' por medida indireta de clorofila. Revista Ciência Agronômica, v. 40, n. 02, p. 266-271, 2009.
VIEIRA, F. de C. et al. Importância da adubação na cultura da batata. Batata Show, v. 02, n. 05, p. 16-17, 2002.

VOS, J.; BOM, M. Hand-held chlorophyll meter: a promising tool to asses the nitrogen status of potato foliage. Potato Research, v. 36, n. 04, p. 301-308, 1993.

WU, J. et al. Comparison of petiole nitrate concentrations, SPAD chlorophyll readings, and QuickBird satellite imagery in detecting nitrogen status of potato canopies. Field Crops Research, v. 101, p. 96-103, 2007.

YIN, X. et al. Some quantitative relationships between leaf area index and canopy nitrogen content and distribution. Annals of Botany, v. 91, n. 07, p. 893- 903, 2003. 